\title{
Influence of non-nutritive sucking habits on anterior open bite
}

\author{
Ana de Lourdes Sá de Lira ${ }^{1, *}$ (iD, Alice Rodrigues Santos ${ }^{1}$
}

${ }^{1}$ State University of Piauí - UESPI, School of Dentistry, Department of Clinical Dentistry, Area of Integrated Clinic, Parnaíba, PI, Brazil
Corresponding author:

*Corresponding author: Ana de Lourdes Sá de Lira

State University of Piauí, School of Dentistry

Rua Senador Joaquim Pires

2076 Ininga.

Fone (86) 999595004

CEP: 64049-590 Teresina-PI-Brasil email: anadelourdessl@hotmail.com

Received: November 12, 2019

Accepted: May 02, 2020

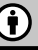

Aim: To evaluate the clinical behavior of sucking habits in children between 2 to 6 years old in a private (A1) and a public school (A2) in the state of Piauí. Methods: It was cross-sectional and quantitative study in 340 participants, 169 in A1 and 171 in A2. The researchers asked the children evaluated to keep their teeth occluded while analyzing whether there was no contact between the anterior teeth and no lip sealing, characterizing the anterior openbite for G1 or if there was contact between the incisors, with lip sealing, characterizing the control group (G2). Results: There was no statistically significant difference between groups regarding bottle feeding at main meals $(\chi 2=3.03 ; p=0.08)$. However, regarding the use of a pacifier, there was a statistically significant association ( $\chi 2=17.99 ; p<0.01$ ) between pacifier use and the presence of anterior openbite. Such association was also observed between digital sucking habit and malocclusion $(\alpha 2=8.99 ; p=0.01)$. Only the parents of the children with anterior openbite noticed the disharmony in the occlusion. It can be deduced that there was an awareness of parents /guardians about the disharmony generated by nonnutritive sucking habits. Conclusion: Nonnutritive sucking habits influenced the appearance of the anterior open bite in children with deciduous dentition. Nonnutritive sucking habits, such as digital sucking and pacifiers, are significantly associated with the presence of anterior open bite. Breastfeeding is important in preventing this malocclusion.

Keywords: Open bite. Malocclusion. Sucking behavior. 


\section{Introduction}

Open bite can be defined as a deficiency in normal vertical contact between antagonist teeth and may manifest in a limited region or, more rarely, throughout the dental arch. If the lack of contact of the teeth is located in the incisors and / or canines region, and when the occlusion is in centric relation, it is renamed anterior open bite ${ }^{1-3}$.

This malocclusion has a multifactorial origin and is almost always associated with an orofacial myofunctional disharmony, either due to hereditary or environmental factors. Among the environmental factors we can mention the presence of harmful sucking habits ${ }^{1,4}$.

Basically there are two types of suction, the first for nutritional purposes, which refers to breastfeeding itself, providing essential nutrients for the child's growth, and the second for non-nutritive purposes, such as the sucking of fingers and pacifiers, which provides a sensation pleasant safety and welfare ${ }^{5}$.

Suction is a natural reflection of the human being and has been present since intrauterine life. This maneuver involves various structures such as the tongue, cheeks and lips, and stimulates the normal growth of the jaws and stomatognathic structures. In early life, this habit is related to the child's diet and nutrition, as well as psychological and emotional development aspects ${ }^{5,6}$.

However, this habit can become deleterious if sustained for a prolonged period, which may alter the normal growth pattern and damage the occlusion. Damage will be determined by the frequency, duration, intensity and the object used, as well as the age of the individual at the time of its installation ${ }^{6,7}$.

Regarding the endless nutritional habit, the most found in children are those of digital suction and sprinkles, being prevalent in the first years of the child's life tending to decrease with age. Both forms of suction promote similar changes in peribucal musculature and occlusion, however it is suggested that due to the difficulty in interrupting digital suction, this habit may result in greater deleterious effects. However, if the deleterious oral habit persists until three years of age, there is a chance of self-correction of possible occlusal disharmonies present ${ }^{6}$.

Children with non-nutritive sucking habits have a high prevalence of anterior openbite, showing a significant association between the presence of deleterious sucking habits and the occurrence of malocclusion ${ }^{8,9}$. In 2004 the prevalence of this malocclusion in preschoolers in Brazil was $24 \%{ }^{10}$. On the other hand, in 2012 the prevalence in a city in the northeast was $20.3 \%{ }^{11}$.

It is expected to find out in this study low prevalence of anterior openbite due to the guidance received by their prenatal mothers and medical and dental consultations on the importance of breastfeeding and preventive measures on nonnutritive sucking habits.

Based on this context, it belived that the non-nutritive sucking habit, such as finger and pacifier sucking, may predispose the installation of the anterior open bite, taking into account that the longer the duration and frequency of the habit, as well as the intensity of the force applied, the greater the severity of the malocclusion. Hence, it is 
important to increase our understanding of the association of non-nutritive sucking habit with alterations in occlusion and oral myofunction in preschool children who are being introduced to oral health care. This would provide pediatric dentists with clinical evidence to guide the children's parents and guardians.

We wanted to conduct this research to investigate whether there is an association between non-nutritive sucking habits and anterior open bite. This research aimed to evaluate the clinical behavior of sucking habits in children between 2 to 6 years old in a private (A1) and a public school (A2) in the state of Piauí.

\section{Materials and Methods}

This study was approved by the Research Ethics Committee of the State University of Piauí - CEP / UESPI, under number 2.537.169. It was cross-sectional observational study, from August to December 2018, whose sample size calculation was based on the target population: children between 2 and 6 years old, specifically in the preschool phase of Parnaíba in 2018, totaling 4.087 students.

The required sample size was 350 participants, according to the inclusion criteria, as the population representative of the municipality of Parnaíba-PI. This minimum number of participants was considered sufficient considering the proposed analyzes, the $5 \%$ sampling error, and the $95 \%$ confidence level, indicating that the probability of the research error does not exceed $5 \%{ }^{12}$. However due to the parents' lack of interest in answering the questionnaire and signing the consent form, only 340 children were allowed to participate, 169 in private school (A1) and 171 in municipal public school (A2).

Inclusion criteria were children in primary dentition, with or without non-nutritive sucking habit (pacifier or digital). Those who presented anterior open bite were named G1 and those without this malocclusion were classified as G2, between 2 and 6 years old, whose parents or guardians and the children accepted the research. As exclusion criteria, children under 2 years, because the deciduous dentition would not be fully formed, and those over 6 years old, because they were already in mixed dentition and children whose parents or guardians did not authorize the research. The anterior open bite is characterized by the lack of normal vertical contact between the antagonistic teeth, located in the region of incisors and / or canines 4 .

To the parents or guardians of the children were sent a questionnaire prepared by the researchers about non-nutritive oral habits, such as pacifier use and / or digital sucking, as well as breastfeeding history. The questionnaire was based on studies made for the elaboration of this research, containing questions related to the type of breastfeeding (natural and / or artificial), non-nutritive oral habits (pacifier and / or digital sucking), frequency and duration of habits and perception of breastfeeding and parents or guardians perception of the presence of anterior openbite in the child (Figure 1).

The questionnaire used in this research was previously tested and applied by Ling et al. ${ }^{7}$ to carry out an integrative review of the literature on the clinical behavior of sucking habits in children between 2 to 6 years.

Two researchers were calibrated with the pilot study by examining ten children who sought care at the Clinic School of Dentistry (CEO) of the State University of Piauí 
Respond according to the characteristics you observe in the child.

1. Regarding breastfeeding:

A ( ) Exclusive breastfeeding up to six months

$B$ ( ) Breastfeeding combined with bottle feeding

C ( ) Exclusive use of bottle

2. Do you currently use a bottle to supplement your diet?

$A()$ Yes $B($ ) No

3. Had/are you in the habit of using a pacifier?

A ( ) Yes B ( ) No

4. Had/have a digital sucking habit (finger sucking)?

A ( ) Yes B( ) No

5. If yes to questions 3 and/or 4 , what is the frequency and duration of these habits?

A ( ) All day long

$B$ ( ) At long intervals during the day

C ( ) At short intervals during the day

D ( ) All night long

$E($ ) At long intervals during the night

$F($ ) At short intervals at night

6. Do you notice any disharmony in your child's smile?

$A()$ Yes $B($ ) No

Figure 1. Questionnaire applied to the survey

(UESPI) Campus of Parnaíba, to identify the presence of anterior open bite and this analysis according to the methodology described by Peres et al. ${ }^{13}$.

The pilot study involving 10 children not participating in the sample, randomly chosen 5 for each gender attended at the CEO, aimed to test the proposed methodology. Two examinations separated by an interval of 10 days were performed for each child. Intra-examiner reliability for all variables was evaluated using the kappa statistic. The Kappa coefficient for intra- and inter-examiner agreement being 0.87 and 0.85 , respectively.

For clinical evaluation, each evaluated child was asked to keep the teeth occluded while the evaluators separated the lips with the index finger and thumb, observing if there was no contact between the anterior teeth and absence of lip sealing, characterizing the anterior opebite for G1. If there was contact between the incisors, with lip sealing, the child would participate in the control group G2. The biosafety norms recommended, such as the use of gloves and mask, were taken into consideration, and the examination was performed under natural light, with the child comfortably positioned in front of the examiners.

\section{Statistical Methodology}

The results were stored in the Excel Windows 2010 Microsoft $®$ database and arranged in graphs and tables for better interpretation and discussion. Averages, dispersion and chi-square test were applied to compare the results between $\mathrm{A} 1$ and $\mathrm{A} 2$ and between G1 and G2 and to identify occlusion that was significantly associated with non-nutritive sucking habits, with 95\% statistical significance.

\section{Results}

From the tabulation of the participants' data, it was observed that the average age was 3.87 years $(S D=1.46)$. It was possible to verify the association between 
presence/absence of MAA and sample feeding habits. For this, a chi-square association test was performed, with a statistical significance level of $5 \%$, with its results presented in cross-tables, described below.

From the results it was observed that most children in $\mathrm{G} 1$ used the combination of bottle feeding and breastfeeding for up to six months ( $\mathrm{n}=30)$, and those in $\mathrm{G} 2$ had exclusive breastfeeding ( $n=217)$. This result was statistically significant $(\chi 2=22.95 ; p<0.01)$.

As seen in Table 1, there was no statistically significant difference between the groups regarding bottle feeding at main meals $(\chi 2=3.03 ; p=0.08)$. However, regarding pacifier use, there was a statistically significant association $(\chi 2=17.99 ; p<0.01)$ between pacifier use and the presence of anterior openbite. Such association was also observed between digital sucking habit and malocclusion $(\chi 2=8.99 ; p=0.01)$.

Regarding the perception of some disharmony in their child's smile, the most parents who did not have the malocclusion (G2) did not notice it, while the parents of those who presented it (G1) reported noticing the disharmonic smile $(\chi 2=17.65 ; p<0.01)$. The comparison between $\mathrm{G} 1$ and $\mathrm{G} 2$ regarding these variables was shown in Figure 2.

Table 1. Comparison between $\mathrm{G} 1$ and $\mathrm{G} 2$ regarding the studied variables

\begin{tabular}{|c|c|c|c|c|c|}
\hline Variables & Answers & G1 & G2 & $\chi^{2}$ & p Valor \\
\hline \multirow{2}{*}{ Bottle at meals } & Yes & 34 & 122 & \multirow{2}{*}{3.03} & \multirow{2}{*}{0.08} \\
\hline & No & 17 & 167 & & \\
\hline \multirow{2}{*}{ Pacifier use } & Yes & 37 & 57 & \multirow{2}{*}{17.99} & \multirow{2}{*}{0.01} \\
\hline & No & 14 & 231 & & \\
\hline \multirow{2}{*}{ Digital suction } & Yes & 17 & 20 & \multirow{2}{*}{8.99} & \multirow{2}{*}{0.01} \\
\hline & No & 34 & 269 & & \\
\hline Smile disharmony perception & Yes & 31 & 38 & 17.65 & 0.01 \\
\hline
\end{tabular}

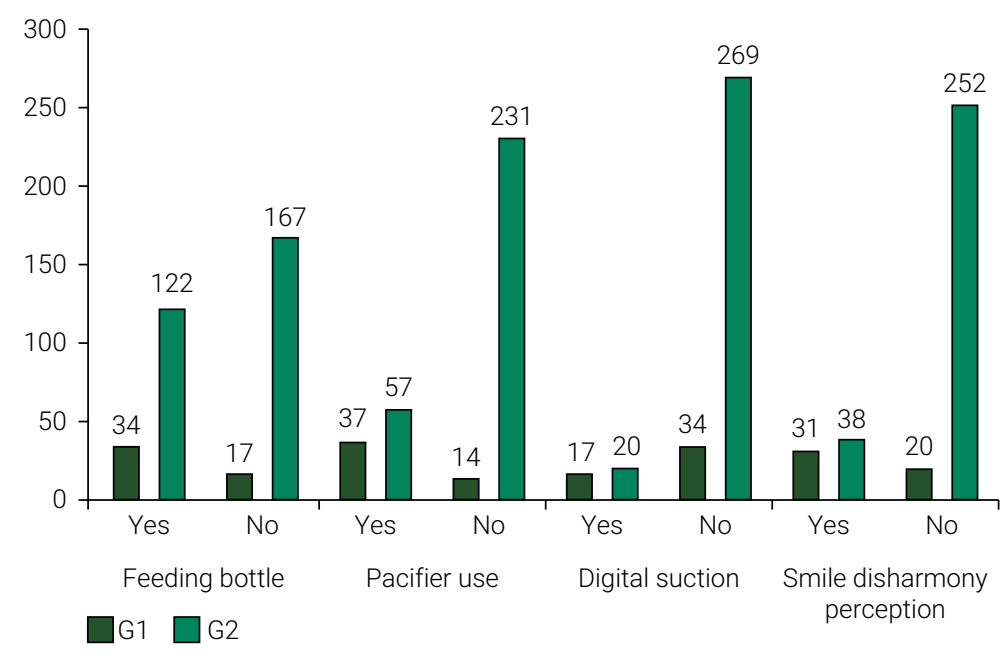

Figure 2. Graphical representation of the comparison between $\mathrm{G} 1$ and $\mathrm{G} 2$ in relation to the studied variables. 
As represented in Figure 3, for those participants who answered positively to questions about pacifier and digital sucking habits, they were asked to state the frequency. The results presented indicated that the majority (33.3\%) presented this habit during the day, with short intervals.

According to Table 2 in both A1 and A2, the number of children who had exclusive breastfeeding up to six months without openbite was significant.

Based on Table 3 in both schools (A1 and A2) there was an association between non-nutritive sucking habits and anterior openbite (G1). Only the parents were able to perceive the disharmonious smile of $\mathrm{G} 1(\chi 2=7.12 ; \mathrm{p}<0.00)$. However, there was no significant difference between $A 1$ and $A 2$ when only $G 1$ and $G 2$ were evaluated separately.

There was no significant difference between genders in both schools when $\mathrm{G} 1$ and G2 were evaluated. However, when genders were evaluated separately for G1 and G2, it was found that for both genders the number of children without anterior openbite was significantly higher for those who were exclusively breastfed until 6 months of age (Table 4).

Table 5 shows that bottle feeding at the main meals did not significantly influence the anterior openbite in both genders and that the parents did not statistically perceive the disharmony of the smile in female children.

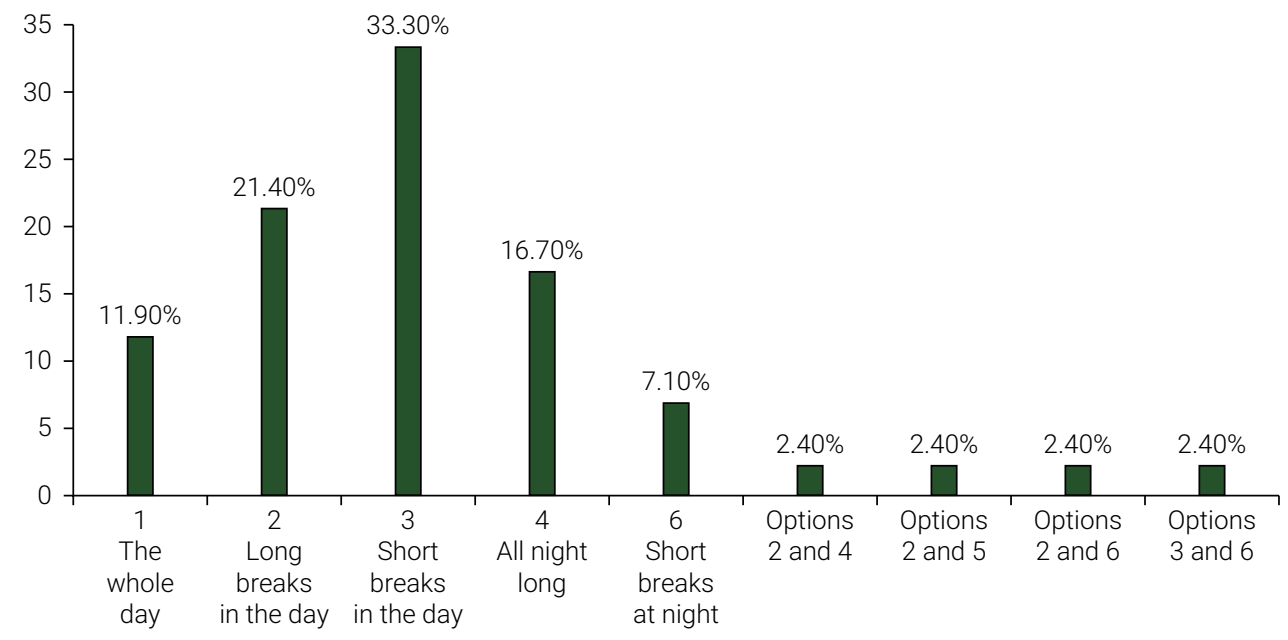

Figure 3. Graphical representation of frequency and duration of sucking habits

Table 2. Type of food up to six months old between $\mathrm{G} 1$ and $\mathrm{G} 2$ of $\mathrm{A} 1$ and $\mathrm{A} 2$.

\begin{tabular}{|c|c|c|c|c|c|c|c|c|}
\hline \multirow{3}{*}{ Food up to six months old } & \multicolumn{8}{|c|}{ Groups } \\
\hline & \multicolumn{2}{|c|}{$\mathrm{A} 1$} & \multirow{2}{*}{$\chi^{2}$} & \multirow{2}{*}{$\mathrm{p}$ valor } & \multicolumn{2}{|c|}{$\mathrm{A} 2$} & \multirow{2}{*}{$\chi^{2}$} & \multirow{2}{*}{$\mathrm{p}$ valor } \\
\hline & G1 & G2 & & & G1 & G2 & & \\
\hline Breastfeed only & 0 & 107 & \multirow{3}{*}{12.35} & \multirow{3}{*}{0.00} & 7 & 110 & \multirow{3}{*}{11.18} & \multirow{3}{*}{0.00} \\
\hline Combined feeding & 17 & 38 & & & 13 & 20 & & \\
\hline Bottle only & 4 & 4 & & & 10 & 10 & & \\
\hline
\end{tabular}


Table 3. Analysis of sucking habits and perception of disharmony between G1 and G2 of A1 and A2.

\begin{tabular}{|c|c|c|c|c|c|c|c|c|c|}
\hline \multirow{2}{*}{ Variables } & \multirow{2}{*}{ Answers } & \multicolumn{2}{|c|}{ A1 } & \multirow{2}{*}{$\chi^{2}$} & \multirow{2}{*}{$\mathrm{p}$ valor } & \multicolumn{2}{|c|}{$\mathrm{A} 2$} & \multirow{2}{*}{$\chi^{2}$} & \multirow{2}{*}{$\mathrm{p}$ valor } \\
\hline & & G1 & G2 & & & G1 & G2 & & \\
\hline \multirow{2}{*}{ Bottle at meals } & Yes & 10 & 45 & \multirow{2}{*}{0.93} & \multirow{2}{*}{0.33} & 23 & 77 & \multirow{2}{*}{1.62} & \multirow{2}{*}{0.20} \\
\hline & No & 10 & 103 & & & 7 & 64 & & \\
\hline \multirow{2}{*}{ Pacifier use } & Yes & 14 & 24 & \multirow{2}{*}{7.67} & \multirow{2}{*}{0.00} & 23 & 33 & \multirow{2}{*}{9.71} & \multirow{2}{*}{0.00} \\
\hline & No & 7 & 124 & & & 7 & 107 & & \\
\hline \multirow{2}{*}{ Digital suction } & Yes & 10 & 10 & \multirow{2}{*}{9.07} & \multirow{2}{*}{0.00} & 7 & 10 & \multirow{2}{*}{4.90} & \multirow{2}{*}{0.05} \\
\hline & No & 10 & 138 & & & 23 & 131 & & \\
\hline \multirow{2}{*}{$\begin{array}{l}\text { Smile disharmony } \\
\text { perception }\end{array}$} & Yes & 10 & 14 & \multirow{2}{*}{7.12} & \multirow{2}{*}{0.00} & 21 & 23 & \multirow{2}{*}{9.75} & \multirow{2}{*}{0.00} \\
\hline & No & 10 & 134 & & & 10 & 117 & & \\
\hline
\end{tabular}

Table 4. Comparison of feeding up to six months between G1 and G2 in male and female.

\begin{tabular}{|c|c|c|c|c|c|c|c|c|}
\hline \multirow{3}{*}{ Food up to six months old } & \multicolumn{8}{|c|}{ Groups } \\
\hline & \multicolumn{2}{|c|}{ Male } & \multirow{2}{*}{$\chi^{2}$} & \multirow{2}{*}{$\mathrm{p}$ valor } & \multicolumn{2}{|c|}{ Female } & \multirow{2}{*}{$\chi^{2}$} & \multirow{2}{*}{ p valo } \\
\hline & G1 & G2 & & & G1 & G2 & & \\
\hline Breastfeed only & 0 & 119 & \multirow{3}{*}{3.01} & \multirow{3}{*}{0.00} & 7 & 99 & \multirow{3}{*}{7.32} & \multirow{3}{*}{0.02} \\
\hline Combined feeding & 17 & 37 & & & 13 & 20 & & \\
\hline Bottle only & 7 & 0 & & & 7 & 14 & & \\
\hline
\end{tabular}

Table 5. Evaluation of smile sucking and disharmony habits between G1 and G2 regarding gender.

\begin{tabular}{|c|c|c|c|c|c|c|c|c|c|}
\hline \multirow{2}{*}{ Variables } & \multirow{2}{*}{ Answers } & \multicolumn{2}{|c|}{ Male } & \multirow{2}{*}{$\chi^{2}$} & \multirow{2}{*}{$\mathrm{p}$ valor } & \multicolumn{2}{|c|}{ Female } & \multirow{2}{*}{$\chi^{2}$} & \multirow{2}{*}{$\mathrm{p}$ valor } \\
\hline & & G1 & G2 & & & G1 & G2 & & \\
\hline \multirow{2}{*}{ Bottle at meals } & Yes & 17 & 51 & \multirow{2}{*}{3.89} & \multirow{2}{*}{0.06} & 17 & 71 & \multirow{2}{*}{0.20} & \multirow{2}{*}{0.65} \\
\hline & No & 7 & 105 & & & 10 & 61 & & \\
\hline \multirow{2}{*}{ Pacifier use } & Yes & 20 & 27 & \multirow{2}{*}{14.59} & \multirow{2}{*}{0.00} & 17 & 30 & \multirow{2}{*}{4.93} & \multirow{2}{*}{0.02} \\
\hline & No & 3 & 129 & & & 10 & 102 & & \\
\hline \multirow{2}{*}{ Digital suction } & Yes & 3 & 7 & \multirow{2}{*}{4.12} & \multirow{2}{*}{0.02} & 13 & 14 & \multirow{2}{*}{7.42} & \multirow{2}{*}{0.00} \\
\hline & No & 20 & 150 & & & 13 & 119 & & \\
\hline \multirow{2}{*}{$\begin{array}{l}\text { Smile disharmony } \\
\text { perception }\end{array}$} & Yes & 24 & 10 & \multirow{2}{*}{34.68} & \multirow{2}{*}{0.00} & 7 & 27 & \multirow{2}{*}{4.08} & \multirow{2}{*}{0.05} \\
\hline & No & 0 & 146 & & & 20 & 105 & & \\
\hline
\end{tabular}

\section{Discussion}

There was immediate benefit to the children who participated in the research, when their parents / guardians became aware of the existence of anterior openbite and the harm caused by non-nutritive sucking habits. It has been reported that children under 3 years of age may have their anterior open bite corrected if deleterious sucking habits are removed ${ }^{14}$.

It was found by Moimaz et al. ${ }^{14}$ (2013), in similar studies of sucking habits $44.4 \%$ of the evaluated children had a pacifier sucking habit and did not receive breast milk exclusively until six months of age. These findings reinforce the data found in this 
research, in which there was a predominance of breastfeeding combined with bottle-feeding or bottle-feeding up to six months of age in children with anterior openbite.

Of the 224 children who received exclusive breastfeeding by the age of six months, only 7 developed the malocclusion because they used a pacifier. Similar results were obtained in the study by Pereira et al. ${ }^{15}$ (2018). It was found that $96.6 \%$ of preschool children who had some habit of deleterious sucking, exclusively fed on the bottle. They also found a decrease in the number of children who developed finger and / or pacifier sucking when breastfed for more than 6 months, confirming that this practice is a protective factor for the development of conditions that may negatively affect child occlusion.

The present study showed the direct relationship between non-nutritive sucking habits and the development of the malocclusion. This was confirmed because all children with MAA used pacifiers or digital suction. Bottle feeding at the main meals did not influence the onset of malocclusion, since there was no significant difference between G1 and G2. This was due to the fact that of the 51 children in G1, 17 did not use the bottle, but had the deleterious habit of digital sucking (Table 1 and Figure 2). These findings corroborate those found in studies by Eslamipour et al. ${ }^{3}$ (2018), conducted in children aged 3 to 5 years, whose prevalence of open bite was $20 \%$. The risk of anterior openbite was 3 times higher in children who did digital sucking and almost 5 times higher than do used pacifiers, when compared to those who did not have such habits. In a study by Macho et al. ${ }^{16}$ (2012), it was found that $34.1 \%$ of the sample with deleterious oral habits had malocclusions. Thus, $51.8 \%$ of children with pacifier sucking habits and $19.6 \%$ of children with digital sucking habit had this malocclusion.

According to studies by Bona et al. ${ }^{17}$ (2016), the non-nutritive sucking habit does not always cause occlusion anomalies. In their research, despite the high incidence of malocclusions in the sucking habit group, it was observed that a small percentage of children who presented occlusion changes did not have sucking habits, contrary to the findings of our study. However, the same author stated that the severity of malocclusion depends on the frequency, intensity and duration of the habit, corroborating our research, in which children who presented with openbite and a habit of digital sucking and / or pacifiers maintained these habits in high frequency and intensity. (Figure 3).

In studies by Garbin et al. ${ }^{18}$ (2014) which was performed on preschool children, it has been showed $42.7 \%$ of the children used pacifiers for more than 6 hours daily. These evidences were similar to those found in our study, in which $33 \%$ of participants using pacifiers and / or digital sucking had these habits during the day, with short intervals, followed by $21.4 \%$ with long intervals during the day (Figure 3 ).

Only the parents of the children with anterior openbite noticed the disharmony in the occlusion. It can be deduced that there was an awareness of parents / guardians about the disharmony generated by non-nutritive sucking habits (Table 1). These data corroborate another literature study by Garbin et al. ${ }^{18}$ (2014), in which $97.1 \%$ of parents / guardians believed that non-nutritive sucking habits could cause harm to children's teeth. $42.25 \%$ of them reported that they knew the possible damage, but only $33.3 \%$ pointed out that they had already tried to remove the habit. 
When $\mathrm{G} 1$ and $\mathrm{G} 2$ from schools $\mathrm{A} 1$ and $\mathrm{A} 2$ were compared, it was found that in both schools was significant the number of children from $\mathrm{G} 2$ who were exclusively breastfed until 6 months of age, emphasizing the importance of breastfeeding in preventing malocclusions. This was reinforced by the fact that in A2 only 7 of the 51 children with anterior openbite were fed to the breast, but used pacifiers (Table 2).

Continuing this comparison, there was a significant difference between G1 and G2 in both schools regarding deleterious oral habits, suggesting their importance in the installation of the malocclusion (Table 3), as observed by other authors, 5, 17,19-21 by stating that the frequency, duration and intensity of non-nutritive sucking habits are determining factors for the installation of it.

When genders were assessed separately, the number of G2 children in both genders who were exclusively breastfed until 6 months of age and did not develop the malocclusion was significant statistically (Table 4). Similar results were observed by other authors ${ }^{16,22,23}$, emphasizing that the benefits of breastfeeding include the promotion of stomatognathic system development. Cavalcanti et al. ${ }^{24}$ (2007), in their research found that the frequency of sucking habits was higher among children with artificial feeding than in children with natural feeding, reinforcing the importance of breastfeeding.

According to Table 5, there was a significant difference between G1 and G2 regarding the use of pacifiers and digital sucking, demonstrating that they favored the development of MAA in both genders indistinctly, corroborating the findings of other authors ${ }^{20,25-30}$ by emphasizing that such habits may compromise the stomatognathic system similarly in both genders.

There is a higher prevalence and risk of developing malocclusions, such as class II canine relationship, a posterior crossbite and anterior open bite, among children with primary dentition who have a history of suboptimal breast-feeding ${ }^{31}$.

The results of the present study found that the non-nutritive sucking habit, such as finger and pacifier sucking, may predispose the installation of the anterior open bite. It should be emphasized the importance of recognizing early occlusal and myofunctional changes caused by non-nutritive sucking habit in young children.

As a limitation of the study, the need to carry out a larger sample in several schools is emphasized in order to test the reproducibility of the findings.

Future studies on the relationship between nonnutritive sucking habits and anterior open bite are important.

\section{Conclusion}

Nonnutritive sucking habits influenced the appearance of the anterior open bite in children with deciduous dentition.

Nonnutritive sucking habits, such as digital sucking and pacifiers, are significantly associated with the presence of anterior open bite.

Breastfeeding is important in preventing this malocclusion. 


\section{References}

1. Antunes LS, Teixeira EC, Gomes IF, Almeida MH, Mendes PP, Antunes LAA. [Causal relationship between the oral habits, feeding and malocclusion in children deciduous teeth]. Cient Cienc Biol Saúde. 2015;17(2):75-80. Portuguese.

2. Wajid MA, Chandra P, Kulshrestha R, Singh K, Rastogi R, Umale V. Open bite malocclusion: an overview. J Oral Health Craniofac Sci. 2018;3(3):11-20. doi: 10.29328/journal.johcs.1001022.

3. Eslamipour F, Afshari Z, Najimi A. Prevalence of malocclusion inpermanent dentition of Iranian population: a review article. Iran J Public Health. 2018 Feb;47(2):178-87.

4. Artese A, Drummond S, Nascimento JM, Artese F. Criteria for diagnosing and treating anterior open bite with stability. Dental Press J Orthod. 2011 May-June;16(3):136-61. Portuguese. doi: 10.1590/S2176-94512011000300016.

5. Grochentz JBG, Laginski MCS, Dalledone M, Bruzamolin CD. Marques, FR. [Sucking not nutritional habits and the relationship with malocclusions]. Rev Gestao Saude. 2017 Jan/Mar;16(01):12-20. Portuguese.

6. Gisfred TF, Kimura JS, Reyes A, Bassi J, Drugowick R, Matos R, et al. [Deleterious oral habits and its consequences in Pediatric Dentistry]. Rev Bras Odontol. 2016 Apr/Jun;73(2):144-9. Portuguese.

7. Ling HTB, Sum FHKMH, Zhang L, Yeung CPW, Li KY, Wong HM, et al. The association between nutritive, non-nutritive sucking habits and primary dental occlusion. BMC Oral Health. 2018;18(1):145-55. doi: 10.1186/s12903-018-0610-7.

8. Domann J, Cruz, CM, Crepaldi MV, Crepaldi MLS, Oliveira BLS. [Bite back open, etiology, early diagnosis and treatment]. Rev FAIPE. 2016 Jul-Dez;6(2):1-14. Portuguese.

9. Rosa GN, Del Fabro JP, Tomazoni F, Tuchtenhagen S, Alves LS, Ardenghi TM. Association of malocclusion, happiness, and oral health-related quality of life (OHRQoL) in schoolchildren. J Public Health Dent. 2016 Mar;76(2):85-90. doi: 10.1111/jphd.12111.

10. Katz CR, Rosenblatt A, Gondim PP. Nonnutritive sucking habits in Brazilian children: effects on deciduous dentition and relationship with facial morphology. Am J Orthod Dentofacial Orthop. 2004 Jul;126(1):53-7. doi: 10.1016/j.ajodo.2003.06.011.

11. Magalhães LNC, Rodrigues MJ, Heimer MV, Alencar AS. Prevalence of non-nutritive sucking habits and its relation with anterior open bite in children seen in the Odontopediatric Clinic of the University of Pernambuco. Dental Press J Orthod. 2012 Mar-Apr;17(2):119-23. doi: 10.1590/S2176-94512012000200021.

12. Luchesa CJ. Chaves Neto A. [Calculation of sample size in administration research]. Curitiba: Autor's edition; 2011. Portuguese.

13. Peres MA, Traebert J, Marcenes W. [Calibration of examiners for dental caries epidemiology studies]. Cad Saúde Pública. 2001 Jan-Feb;17(1):153-9. doi: 10.1590/s0102-311×2001000100016. Portuguese.

14. Moimaz SAS, Rocha NB da, Garbin AJI, Saliba O. [The effect of breastfeeding in the acquisition of non-nutritive sucking habits and malocclusion prevention]. Rev Odontol UNESP 2013;42(1):31-6. doi: 10.1590/S1807-25772013000100006. Portuguese.

15. Pereira MBB, Ferreira AP, Bastos NCS, Avelino MAG, Pacheco JF, Duarte MDL, et al. [Association between breastfeeding duration, non-nutritive sucking habits and deglutition in preschool children]. ROBRAC. 2018;27(83):223-8. Portuguese.

16. Macho V, Andrade D, Areia C, Norton A, Coelho A, Macedo P. [Prevalence of deleterious oral habits and occlusal anomalies in a population aged 3-13 years]. Rev Port Estomatol Med Dent Cir Maxilofac. 2012;53(3):143-7. doi: 10.1016/j.rpemd.2012.04.002. Portuguese.

17. Bona AP, Moreira KMS, Tedesco TK, Imparato JCP, Ferreira BD, Reis JB. [Multidisciplinary performance to anterior open bite associated with finger sucking: case report]. Rev Assoc Paul Cir Dent. 2016;70(1):58-63. Portuguese. 
18. Garbin CAS, Garbin AJÍ, Martins RJ, de Souza NP, Moimaz SAS. [Prevalence of non-nutritive sucking habits in preschoolers and parents' perception of its relationship with malocclusions]. Cien Saude Colet. 2014;19(2):553-8. doi: 10.1590/1413-81232014192.23212012. Portuguese.

19. Tomita NE, Bijella VT, Franco LJ. [The relationship between oral habits and malocclusion in preschool children]. Rev Saude Publica. 2000;34(3):299-303. doi: 10.1590/S0034-89102000000300014. Portuguese.

20. Pizzol KEDC, Montanha SS, Fazan ET, Boeck EM, Rastelli ANS. [Prevalence of nonnutritive sucking habits and their relationship to age, gender and type of feeding in preschool children from Araraquara-Brazil]. Rev CEFAC. 2012 May-Jun;14(3):506-15. doi: 10.1590/S1516-18462012005000001. Portuguese.

21. Romagosa DER, Gamboa MRP, Muñiz YA, Oliva LMP, Oliva DE, Naranjo ST. Risk factors associated with deforming oral habits in children aged 5 to 11: a casecontrol study. Medwave. 2014 Mar;14(2):e5927. doi: 10.5867/medwave.2014.02.5927.

22. Oakley LL, Henderson J, Redshaw M, Quigley MA. The role of support and other factors in early breastfeeding cessation: an analysis of data from a maternity survey in England. BMC Pregnancy and Childbirth. 2014 Feb 26;14:88. doi: 10.1186/1471-2393-14-88.

23. Victora CG, Bahl R, Barros AJD, França GVA, Horton S, Krasevec J et al. Breastfeeding in the 21st century: epidemiology, mechanisms, and lifelong effect. Lancet. 2016 Jan;387(30):475-90. doi; 10.1016/S0140-6736(15)01024-7.

24. Cavalcanti AL, Medeiros PKB, Moura C. [Breast-feeding, bottle-feeding, sucking habits and malocclusion in brazilian preschool children]. Rev Salud Publica (Bogota). 2007 Apr-Jun;9(2):194-204 doi: 10.1590/s0124-00642007000200004. Portuguese.

25. Pithon MM, Magno MB, Coqueiro RS, Paiva SM, Marques LS, Paranhus LR, et al. Oral health-related quality of life of children before, during, and after anterior open bite correction: A singleblinded randomized controlled trial. Am J Orthod Dentofacial Orthop. 2019 Sep;156(3):303-11. doi: 10.1016/j.ajodo.2019.04.022.

26. Gomes MC, Clementino MA, Pinto-Sarmento TCA, Costa EMMB, Martins CC, Granville AF, et al. Parental perceptions of oral health status in preschool children and associated factors. Braz Dent $\mathrm{J}$. 2015;26(4):428-34. doi: 10.1590/0103-6440201300245.

27. Nihi VSC, Maciel SM, Jarrus ME, Nihi FM, Salles CLF, Pascotto RC, et al. Pacifier-sucking habit duration and frequency on occlusal and myofunctional alterations in preschool children. Braz Oral Res. 2015;29(1):1-7. doi: 10.1590/1807-3107BOR.

28. Lopes Freire GM, Espasa Suarez de Deza JE, Rodrigues da Silva IC, Butini Oliveira L, Ustrell Torrent JM, Boj Quesada JR. Non-nutritive sucking habits and their effects on the occlusion in the deciduous dentition in children. Eur J Paediatr Dent. 2016;17(4):301-6.

29. Schmid KM, Kugler R, Nalabothu P, Bosch C, Verna C. The effect of pacifier sucking on orofacial structures: a systematic literature review. Prog Orthod. 2018 Mar;19(8):1-11. doi: 10.1186/s40510-018-0206-4.

30. Lima AADSJ, Alves CMC, Ribeiro CCC, Pereira ALP, da Silva AAM, Silva LFGE, et al. Effects of conventional and orthodontic pacifiers on the dental occlusion of children aged 24-36 months old. Int J Paediatr Dent. 2017 Mar;27(2):108-19. doi: 10.1111/ipd.12227.

31. Doğramacı EJ, Rossi-Fedele G, Dreyer CW. Malocclusions in young children: Does breast-feeding really reduce the risk? A systematic review and meta-analysis. J Am Dent Assoc. 2017 Aug;148(8):566-74.e6. doi: 1010.1016/j.adaj.2017.05.018. 